\title{
A US perspective on the shortcomings of PTCA
}

\author{
Spencer B King III
}

In the past decade, significant improvements in the acute outcome of angioplasty (PTCA) have been achieved with mortality rates below $1 \%$ and emergency surgery rates of $1-3 \%$ being met by most institutions. Nonetheless, numerous shortcomings exist. Acute results, as impressive as they are with stenting, effective antiplatelet therapy, and other measures are only the beginning of the story. The long term clinical outcome unfortunately has not shown a dramatic improvement.

It is perhaps ironic that most of the shortcomings of PTCA have been discovered while performing trials to demonstrate improvements in the technique. Trials such as CAVEAT, lovastatin restenosis trial, ${ }^{2}$ and STRESS, ${ }^{3}$ showed that the restenosis rate was $40-50 \%$ in the balloon treated relatively ideal lesions and was only reduced to $32 \%$ when stents were used in STRESS. ${ }^{3}$ The EAST study ${ }^{4}$ showed that multivessel disease patients have a restenosis rate per lesion of $44 \%$. BARI $^{5}$ and EAST ${ }^{4}$ patients had five year survival comparable to randomly assigned surgical patients, however, over $50 \%$ required additional procedures.

Will these clinical results change significantly with new technology anchored by stents? Although restenosis rates have been reduced by one third in STRESS and Benestent $\mathrm{I}^{6}{ }^{6}$ and by $50 \%$ in Benestent $\mathrm{II},{ }^{7}$ these represent the minority of lesions treated. One third of all patients treated at Emory University Hospital have had prior bypass surgery. The SAVED trial ${ }^{8}$ showed a nonsignificant trend towards reduction in restenosis in stented vein grafts. Others have seen stent restenosis rates ranging from $27-40 \%$ in ostial lesions, long lesions, small vessels, restenotic lesions, etc. In-stent restenosis has been a particularly difficult condition to treat successfully.

In the US, $30-40 \%$ of patients treated with PTCA receive stents. Is the fact that only two stent designs are currently approved blunting stent usage and impeding improved results? There are few follow up data on the superiority of the new generation stents, although certain lesions unstentable with available devices could have new generation stents placed. As these applications extend stent use beyond the indications for which we have documented improved restenosis rates, the long term clinical benefit of more extensive stenting must, for the time, remain speculative. Recent experiments using endovascular radiation to reduce recurrent restenosis in stents is encouraging and other methods are also needed. ${ }^{9}$

Finally, the success of PTCA has also become something of a shortcoming. In the US, approximately 6000 cardiologists identified themselves as performers of PTCA. The experience level for many operators is therefore very small. As new technologies emerge, it is crucial that operators have adequate experience. Many practice groups are now concentrating the PTCA experience among a few members, and the American Board of Internal Medicine has established a certificate of added qualification that will certify those with a significant level of training and expertise to be considered board certified interventional cardiologists. This move will help strengthen the discipline so that scientific solutions to the shortcomings of PTCA may be expertly applied to patients.

1 Topol EJ, Leya F, Pinkerton CA, et al. A comparison of directional coronary atherectomy with coronary angioplasty in patients with coronary artery disease. $N$ Engl $\mathcal{F}$ Med 1993;329:221-7.

2 Weintraub WS, Boccuzzi SJ, Brown CL III, et al. Background and methods for the lovastatin restenosis trial after percutaneous transluminal coronary angioplasty. Am $\mathcal{f}$ Cardiol 1992;70:293-9.

3 Fischman DL, Leon MB, Baim DS, et al, for the Stent Restenosis Study Investigators. A randomized comparison of coronary-stent placement and balloon angioplasty in the treatment of coronary artery disease. $N$ Engl $7 \mathrm{Med}$ 1994;331:496-501.

4 King SB III, Lembo NJ, Weintraub WS, et al, for the Emory Angioplasty versus Surgery Trial (EAST). A randomized trial comparing coronary angioplasty with coronary bypass surgery. $N$ Engl $f$ Med 1994;331:1044-50.

5 The Bypass Angioplasty Revascularization Investigation (BARI) Investigators. Comparison of coronary bypass (BARI) Investigators. Comparison of coronary bypass
surgery with angioplasty in patients with multivessel dissurgery with angioplasty in patients with
ease. $N$ Engl $₹$ Med 1996;335:217-25.

6 Serruys PW, de Jaegere P, Kiemeneij F, et al, for the Benestent Study Group. A comparison of balloonexpandable-stent implantation with balloon angioplasty expandable-stent implantation with balloon angioplasty
in patients with coronary artery disease. $N$ Engl $\Im$ Med in patients with

7 Suryapranata $\mathrm{H}$, on behalf of the BENESTENT Study Group. Evolving changes in technique of stent deployment during the course of the BENESTENT-II pilo study [abstract]. Circulation 1995;92:I687.

8 Douglas JS JR, Savage MP, Bailey SR, et al, for the SAVED trial investigators. Randomized trial of coronary stent and balloon angioplasty in the treatment of saphenous vein graft stenosis [abstract]. $\mathcal{F}$ Am Coll Cardiol 1996;27 (suppl A): 178A.

9 Teirstein PS, Massullo V, Jani S, et al. Radiation therapy following coronary stenting- 6 month followup of a randomized clinical trial [abstract]. Circulation 1996;94 (suppl I):I210. 